\title{
Microbial Growth and Changes in Nutritional Contents of Preserved and Unpreserved Fresh Milk Stored at $4^{\circ} \mathrm{C}$
}

\author{
P. O. Adeniji ${ }^{1, *}$, T.E. Eyinla ${ }^{2}$ \\ ${ }^{1}$ Department of Transport and Tourism Studies, Redeemer's University, Ede, Osun State, Nigeria \\ ${ }^{2}$ Department of Human Nutrition, University of Ibadan, Ibadan, Nigeria \\ *Corresponding author: adenijio@run.edu.ng
}

Received April 07, 2019; Revised May 21, 2019; Accepted June 08, 2019

\begin{abstract}
The effects of microbial deterioration and changes in the nutritional contents of preserved and unpreserved fresh cow milk stored at $4^{\circ} \mathrm{C}$ were investigated. Three different concentrations $(0.1 \%, 0.2 \%$ and $0.4 \%)$ of preservatives- benzoic acid (BA) and sodium metabisulphite (SM) were evaluated for anti-microbial impact. The bacterial load and nutritional content were assessed and monitored over days for both treated and untreated milk. The results showed that microorganisms would still grow in milk at $4^{\circ} \mathrm{C}$ with a gradual reduction in nutritional factors. However, upon addition of the selected preservatives, significant reduction in the microbial growth was observed. The efficacy of benzoic acid in reducing bacterial growth was higher across all the levels of treatment especially when $0.4 \%$ concentration of both preservatives were applied and compared against untreated milk. The study concludes that the use of chemical preservation can serve the purpose of prolonging the onset of milk spoilage and reduce food safety concerns in dairy production.
\end{abstract}

Keywords: cow milk, benzoic acid, sodium metabisulphite, food spoilage

Cite This Article: P. O. Adeniji, and T.E. Eyinla, "Microbial Growth and Changes in Nutritional Contents of Preserved and Unpreserved Fresh Milk Stored at $4^{\circ} \mathrm{C}$." Journal of Food and Nutrition Research, vol. 7, no. 6 (2019): 443-446. doi: 10.12691/jfnr-7-6-5.

\section{Introduction}

Milk is the creamy whitish liquid produced from mammary glands of animals and is often described as nature's most nearly perfect single food with numerous nutrients. It is the natural food of the new born mammal and the sole source of nourishment after birth. Humans consume large amounts of milk from animal sources besides human milk. A major source is cow milk which supplies 798 metric tons of worldwide dairy [1]. Milk contains nutrients, including proteins, carbohydrates, fats, minerals, vitamins and water [2]. Milk from human and animal species is a complex biological fluid that contains a wide variety of different constituents which serve immunological and nutritional purposes [2]. Milk is an excellent medium for the growth of bacteria. It contains microorganisms at the time it is drawn from cow, and it may be further contaminated in subsequent handling and processing [3]. With all these benefits, milk is an easily perishable raw material. Contaminating bacteria may multiply rapidly and render it unsuitable for processing and/or unfit for human consumption. The potential growth of spoilage and pathogenic microorganisms in milk and dairy products will affect its quality and shelf-life, as well as its safety $[4,5]$. Bacterial growth can be regulated by refrigeration; thereby slowing down the rate of deterioration. However under certain conditions refrigeration may not be feasible due to economical and/or technical reasons. Difficulties in applying refrigeration are specially a problem for rural areas in developing countries. It would be beneficial to have access to a method, other than refrigeration, for reducing bacterial growth in raw milk during collection and transportation to the dairy processing plant. Benzoic acid and its related compounds possess antimicrobial activity and their preserving quality of benzoic acid is based on its activity to delay the multiplication of several groups of microorganisms especially gram-negative bacteria [6]. Benzoic acid or its sodium salt, benzoate, was the first chemical preservative permitted in foods in the USA and is still widely used in a large number of foods. [6]. It has the advantage that it does not affect the odor or taste of the preserved food, if used in small quantities. Sulfites, including sodium sulfite and sodium metabisulphite, are used as preservatives in processed food products including dried fruits, juices, and wine [7]. They are used to inhibit malolactic bacteria, acetic acid bacteria, and spoilage yeasts and molds. While various studies have been reported to preserve milk and reduce spoilage [8,9], it is however not clear what the impact of the selected preservatives will achieve in reducing microbial growth in cow milk. This study investigates the impact of preservation on nutritional 
properties of cow milk and tests the effectiveness of different concentration of two preservatives (benzoic acid and sodium metabisulphite) on microbial growth in the refrigerated milk.

\section{Materials and Methods}

Fresh cow milk was collected from mature cows bred at the Animal Sciences Unit, Faculty of Agriculture of the University of Ibadan. The milk was obtained in sterile two liter bottles. The samples were immediately taken to the Departments of Microbiology and Human Nutrition for microbial and nutrient content analysis respectively. Nutrient composition was also analyzed at the International Institute of Tropical Agriculture, Ibadan. Experimental treatments of antimicrobials were prepared as follows; $0.1 \%, 0.2 \%$ and $0.4 \%(\mathrm{w} / \mathrm{v})$ each of two selected preservatives-Benzoic acid (B.A) and Sodium metabisulphite (S.M) was added and each sample was mixed thoroughly by inverting the bottles several times. A sample without any added preservative was used as control. All the samples were then stored under refrigeration at $4^{\circ} \mathrm{C}$. Microbial analysis was carried out after dilution of fresh cow milk with sterile distilled water in series of sterile bottles. This was done in in duplicates. A volume of $0.1 \mathrm{ml}$ of each experimental sample was plated in duplicate by spreading method on plate count Agar (PCA). The plates were counted by colony counter. Microbial load was recounted as the coverage number of cells capable of growing into a colony on the Agar plate (viable count) after 48 hours, 96 hours and 144 hours. Nutrient content analyses were carried out using standard methods [10]. The $\mathrm{pH}$ of the samples was determined on a pye-unicam $\mathrm{pH}$ meter with glass electrodes after one day and on the sixth day. The $\mathrm{pH}$ of the samples was measured and recorded when the reading was stable as described in literature [11]. Data was processed using a spreadsheet and presented in tables or graphs.

\section{Results and Discussion}

The nutrient content of preserved and unpreserved milk in four successive days during refrigeration was determined and is presented in Table 1 and Table 2. The compositions of samples on Day 1 of the preserved and unpreserved fresh cow milk were protein (4.25 and 4.00), fat (3.48 and 3.40), lactose (3.2 and 3.00), ash (0.68 and $0.65)$ respectively. The nutrient compositions observed in this investigation were similar to literature values for cow milk [12]. On the fourth day, the composition of protein were found to be 3.96 and 3.96 , fat 4.66 and 4.25 , lactose 3.7 and 3.7, and ash 0.57 and 0.58. For preserved fresh cow milk it was observed that protein reduced slightly with a difference of $6.8 \%$, fat increased with a difference of $33.9 \%, 15.6 \%$ increase for lactose and $16.2 \%$ decrease in ash respectively. For unpreserved fresh cow milk, a difference of $1 \%$ for protein, increase of $25 \%$ for fat, $23.3 \%$ for lactose and $10.3 \%$ decrease for ash. A gradual reduction in nutrient composition was observed in protein and ash contents while a reverse was observed for fat and lactose contents which increased.
Table 1. Nutritional content of preserved fresh cow milk during refrigeration in $\mathrm{g} / \mathbf{1 0 0} \mathrm{g}$

\begin{tabular}{|c|c|c|c|c|}
\hline Day & Protein & Fat & Lactose & Ash \\
\hline 1 & $4.25 \pm 0.05$ & $3.48 \pm 0.02$ & $3.2 \pm 0.01$ & $0.68 \pm 0.05$ \\
\hline 2 & $4.07 \pm 0.02$ & $6.02 \pm 0.05$ & $4.2 \pm 0.05$ & $0.76 \pm 0.02$ \\
\hline 3 & $4.04 \pm 0.01$ & $3.66 \pm 0.05$ & $3.1 \pm 0.05$ & $0.66 \pm 0.01$ \\
\hline 4 & $3.96 \pm 0.05$ & $4.66 \pm 0.00$ & $3.7 \pm 0.01$ & $0.57 \pm 0.05$ \\
\hline
\end{tabular}

The mean represents triplicate measurements.

Table 2. Nutritional composition (g/100g) of unpreserved milk during refrigeration

\begin{tabular}{|c|c|c|c|c|}
\hline Day & Protein & Fat & Lactose & Ash \\
\hline 1 & $4.00 \pm 0.03$ & $3.40 \pm 0.05$ & $3.00 \pm 0.04$ & $0.65 \pm 0.05$ \\
\hline 2 & $3.98 \pm 0.05$ & $5.68 \pm 0.01$ & $4.00 \pm 0.02$ & $0.76 \pm 0.03$ \\
\hline 3 & $4.02 \pm 0.05$ & $3.65 \pm 0.02$ & $3.5 \pm 0.02$ & $0.68 \pm 0.00$ \\
\hline 4 & $3.96 \pm 0.02$ & $4.25 \pm 0.05$ & $3.7 \pm 0.03$ & $0.58 \pm 0.05$ \\
\hline
\end{tabular}

The mean represents triplicate measurements.

Figure 1 - Figure 3 shows the number of colonies (expressed as logarithm count) observed on fresh milk sample at different times (48hours, 96hours and 144hours respectively) and different concentrations (0.1\%, $0.2 \%$ and $0.4 \%$ ) of benzoic acid and Sodium metabisulphite compared with the unpreserved fresh milk (control). It was observed that microbial growth was high in the sample treated with sodium metabisulphite at different concentrations than the one treated with benzoic acid with the difference in log number ranging from about a quarter to $50 \%$ when the two preservatives are compared across concentrations. This implies that benzoic acid was a better preservative for the sampled milk in this study. The results also show least microbial growth at 144hours in sample treated with $0.4 \%$ benzoic acid. On the other hand, sodium metabisulphite gave slightly different growth curves with the treated samples yielding more microbial growth than the benzoic acid curve. However, the higher the concentration of the benzoic acid, the lower the microbial growth in comparison to sodium metabisulphite and the control sample.

Milk is a highly nutritious food that serves as an excellent growth medium for a wide range of microorganisms $[4,8]$. The use of preservatives is common in prolonging shelf life of foods. Contrary to reports from literature [13], the results showed that microorganisms would still grow in milk at $4^{\circ} \mathrm{C}$ with a gradual reduction in nutritional factors [3,8]. This growth is possible since micro-organisms that are psychrotrophic will still be active at low temperatures [9]. However, with the addition of preservatives-benzoic acid and sodium metabisulphite, significant reduction in the microbial growth was observed. Specifically the action of benzoic acid was markedly more efficient than Sodium metabisulphite. A similar observation reporting lower antimicrobial efficacy (of sodium metabisulphite) was presented in an experimental preservation of potatoes [14]. Conversely, benzoic acid reduced the growth of baterial isolates more efficiently in a study on preservation of fruit juices [15]. When the effectiveness of the preservatives was compared across all concentrations, there was a marked difference in the quality of preserved and unpreserved milk as the days 
increased. This implies that without some attempt to preserve cow milk within the first day, its quality will deteriorate which definitely increases food safety concerns. Various legislation documents exist around the world to provide guidance on avoiding milk contamination. To the best our knowledge, such legislation (even if existent) in
Nigeria is not in full adaptation to dairy handling practices. This gap needs to be filled at the policy level to provide a framework for food safety measures against the threats of milk contamination. The results of the $\mathrm{pH}$ of the treated and untreated samples with varying concentrations of the preservatives are shown on Table 3.

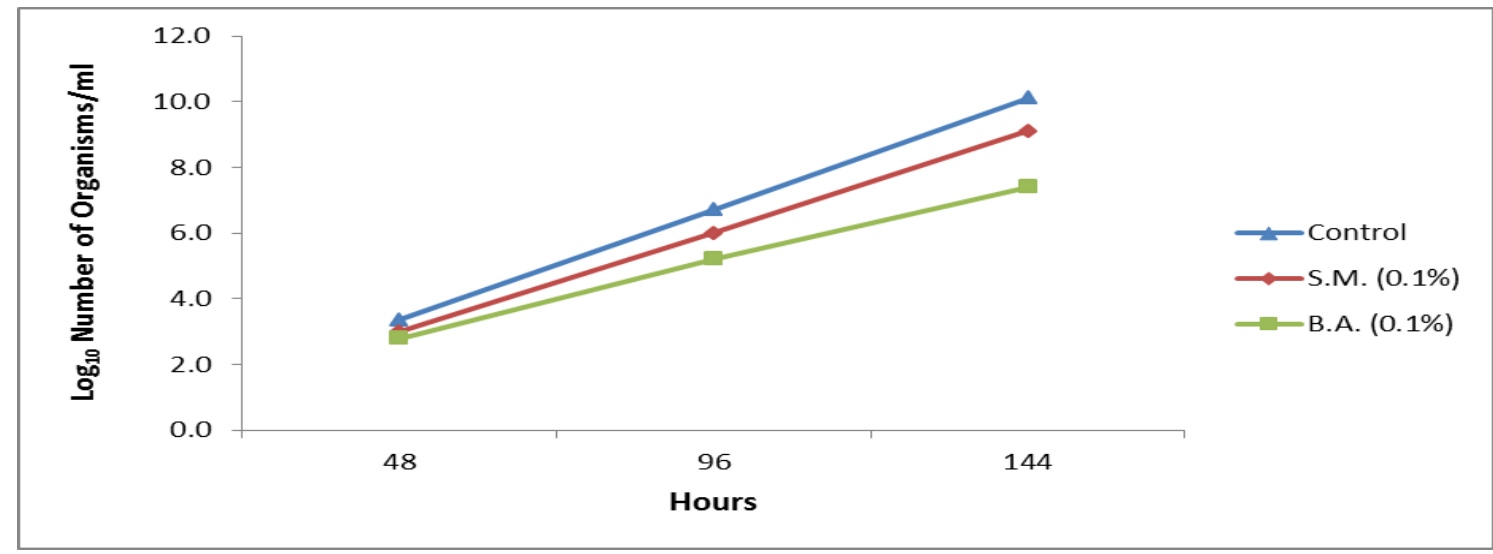

Figure 1. Bacterial growth count in preserved milk ( $0.1 \%$ level) and unpreserved cow milk

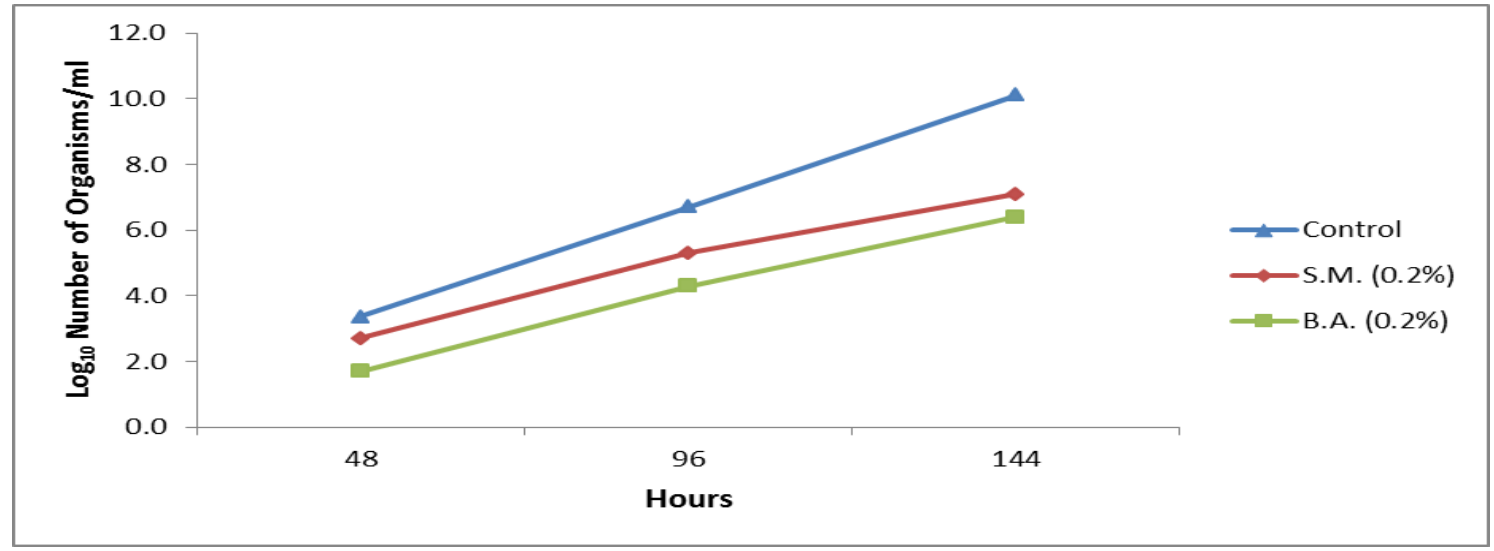

Figure 2. Bacterial count in milk preserved at $0.2 \%$ level compared with unpreserved cow milk

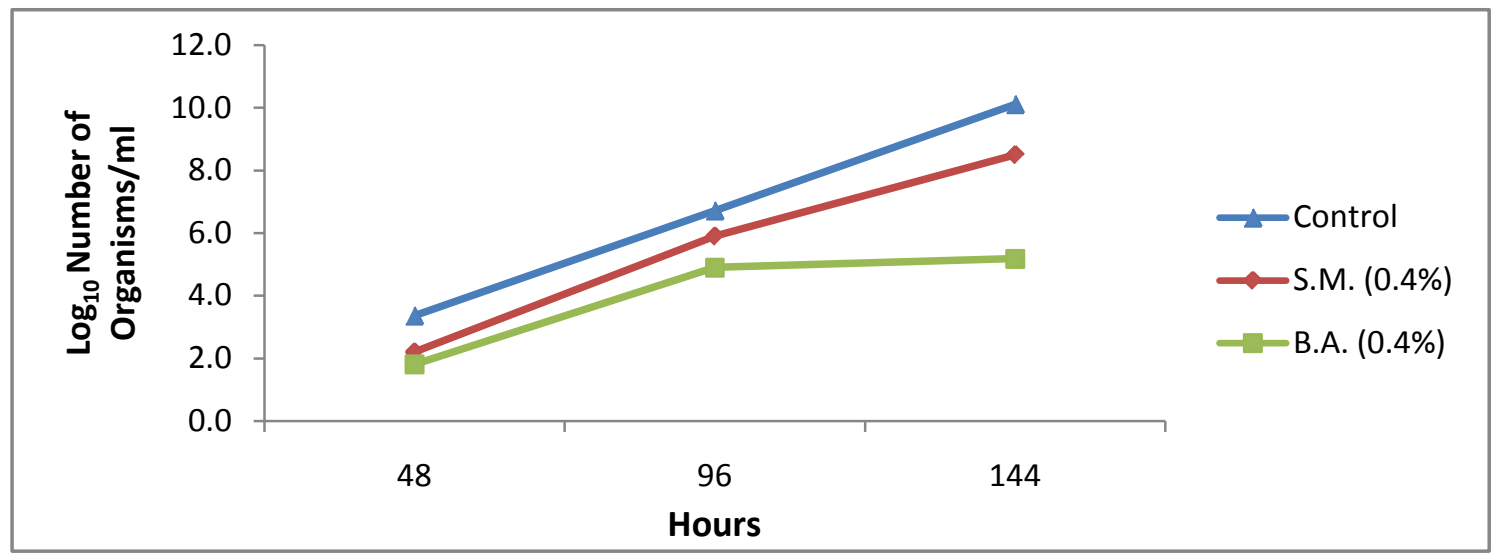

Figure 3. Bacterial growth count in milk containing $0.4 \%$ level of preservatives compared with unpreserved cow milk

Table 3. Changes in $\mathrm{pH}$ of treated and untreated milk samples on different days

\begin{tabular}{|c|c|c|c|c|c|c|c|}
\hline & $\begin{array}{c}\text { B.A } \\
0.1 \% \\
\end{array}$ & $\begin{array}{l}\text { S.M. } \\
0.1 \% \\
\end{array}$ & $\begin{array}{l}\text { B.A. } \\
0.2 \%\end{array}$ & $\begin{array}{l}\text { S.M. } \\
0.2 \% \\
\end{array}$ & $\begin{array}{l}\text { B.A. } \\
0.4 \% \\
\end{array}$ & $\begin{array}{l}\text { S.M. } \\
0.4 \%\end{array}$ & Control \\
\hline Day $1 \mathrm{pH}$ & 6.70 & 7.1 & 6.5 & 7.1 & 6.1 & 7.1 & 7.15 \\
\hline Day 6 pH & 5.0 & 4.8 & 5.3 & 4.8 & 5.6 & 4.9 & 4.8 \\
\hline
\end{tabular}

B.A - Benzoic acid

S.M - Sodium metabisulphite. 
Sample treated with $0.1 \%$ benzoic acid showed $\mathrm{pH}$ of 6.70 initially and decreased to 5.0. Sample treated with $0.2 \%$ benzoic acid showed $\mathrm{pH}$ of 6.5 and decreased to 5.3 . The study shows that the addition of Sodium metabisulphite had little effect on $\mathrm{pH}$. However the $\mathrm{pH}$ of milk will gradually become acidic over time since bacteria in milk convert the sugar lactose into lactic acid. This is reflected in the $\mathrm{pH}$ of the unpreserved milk which reduced from 7.15 to 4.8 .

\section{Conclusion}

This study investigated the impact of storage and addition of preservatives on the nutritional composition of fresh cow milk and also considered the impact of different concentrations of selected preservatives on the microbial deterioration of fresh cow milk. Significant reduction in the microbial growth was observed by the addition of benzoic acid and sodium metabisulphite. The study concludes that the use of chemical preservation can serve the purpose of prolonging the onset of milk spoilage and thus contribute to reducing food safety concerns in dairy production. It is recommended that a further test may be carried out to combine the two preservatives to test if antimicrobial efficacy will increase. A further inquiry into the impact of the selected preservatives on the organoleptic properties is also recommended at the beginning and end of the preservation period. Cow milk being a good media for microbial growth, there should be a national guideline that provides food safety guidelines from extraneous contamination during production, transportation and storage of milk to render it safe for human consumption.

\section{Acknowledgements}

The authors acknowledge Mr Joseph Uponi of IITA, Ibadan and Prof Tope Ogunbamwo of Department of Botany and Microbiology, University of Ibadan for assistance with Nutritional and Microbiological analyses.

\section{References}

[1] Food Agriculture Organization “Global Milk production by Species” FAO 2016

http://www.fao.org/resources/infographics/infographicsdetails/en/c/273893/ [Accessed Mar. 8, 2018].

[2] Jenness, R."Composition of milk." Fundamentals of dairy chemistry, Springer, Boston, MA, 1-38, 1988.

[3] Sarkar, S., "Microbiological Safety Concerns of Raw Milk" Journal of Food Nutrition and Dietetics, 1(2), 1-7, 2016.

[4] Ruegg, P.L., "Practical food safety interventions for dairy production” Journal of Dairy Science. 86, E1-9, Jun 2003.

[5] Rajagopal, M., Werner, B.G., Hotchkiss, J.H., "Low pressure $\mathrm{CO}_{2}$ storage of raw milk: microbiological effects" Journal of Dairy Science, 88(9), 3130-8, Sep 2005.

[6] Jorge, K., "SOFT DRINKS: Chemical Composition" Encyclopedia of human nutrition (Second Edition), Academic press, 2003

[7] Demirci, A., Ngadi, M.O., Microbial decontamination in the food industry: Novel methods and applications. Elsevier, Jun 2012, 26 pp.

[8] in't Veld, J.H., "Microbial and biochemical spoilage of foods: an overview” International Journal of Food Microbiology, 33(1), 1-8, Nov 1996.

[9] Marth, E.H., Steele, J., Applied dairy microbiology, Marcel Dekker, USA, 2001, 22pp.

[10] AOAC Official Methods of Analysis. 17th Edition, The Association of Official Analytical Chemists, Gaithersburg, MD, USA, 2000.

[11] Daniyan, S.Y., Abalaka, M.E., Momoh, J.A., Adabara, N.U., "Microbiological and physiochemical assessment of street vended soyabean cheese sold in Minna, Nigeria”, International Journal of Biomedical and Advance Research, 2(1):25-31, 2011.

[12] Guetouache M, Guessas B, Medjekal S., "Composition and nutritional value of raw milk" Journal Issues, 2(10), 115-122, Dec 2014.

[13] Fagerman, K.E., Paauw, J.D., McCamish, M.A., Dean, R.E., "Effects of time, temperature, and preservative on bacterial growth in enteral nutrient solutions”, American Journal of Health-System Pharmacy, 41(6), 1122-6, Jun 1984.

[14] Giannuzzi, L., Zaritzky, N.E., "Chemical preservatives action on microbial growth in a model system of refrigerated Pre-peeled potatoes” Journal of Food Protection, 56(9): 801-807, Sep 1993.

[15] Oladipo, I.C., Adeleke, D.T., Adebiyi, A.O., "The effect of pH and chemical preservatives on the growth of bacterial isolates from some Nigerian packaged fruit juices” Pakistan Journal of Biological Sciences, 13(1): 16, Jan 2010. 